\title{
TINDAK TUTUR KIAI MENGENAI SYARAH (PENJELASAN) KITAB AL-HIKAM DAN TAFSIR AI-QUR'AN DALAM PENGAJIAN
}

\author{
Deasy Aditya Damayanti \\ Program Studi Pendidikan Bahasa dan Sastra Indonesia STKIP Garut \\ Korespondensi: Jln. Pahlawan No.32 Sukagalih Tarogong Kidul \\ Pos-el: adityadeasy@yahoo.co.id
}

\begin{abstract}
Abstrak
Penelitian ini berawal dari pemikiran bahasa adalah aspek penting dalam mempelajari suatu kehidupan dan kebudayaan masyarakat. Wujud penggunaan bahasa ini biasa terealisasi lewat tindak tutur. Namun, pada umumnya sifat tindak tutur dari sudut pandang budaya internal memiliki banyak penafsiran. Menurut Austin (1962), kajian etnopragmatik ialah kajian tindak tutur karena memperlihatkan kaitan antara penyampaian tuturan kiai dengan nilai budaya masyarakat. Oleh karena itu, peneliti berusaha memotret jenis tindak tutur dan tipe tindak tutur yang terdapat dalam tuturan kiai mengenai syarah (penjelasan) kitab Al-Hikam dan tafsir Al-Qur'an pada ibu-ibu pengajian di masjid Nurul Huda Kampung Cireungit Garut serta kaitan antara penyampaian tuturan kiai dengan nilai-nilai budaya masyarakatnya.
\end{abstract}

Kata-Kata Kunci: tindak tutur, syarah (penjelasan) Al-Hikam, Tafsir Al-Quran, etnopragmatik, nilai budaya

\begin{abstract}
This study is motivated by the notion that language is an important aspect in examining social life and culture. The use of language is realized through speech acts. However, the nature of the speech acts from the stand point of internal culture has many interpretations. According to Austin (1962), an etnopragmatic study is a study of speech acts that reveals an association between delivery of speech of the Kiai (the scholar) and the cultural values of the society. Therefore, this study seeks to capture the type of speech acts contained in the speech of Syarah (explanation) of Al-Hikam and Interpretation of the Koran recitation in a religious lecture for mothers in the Nurul Huda Mosque in Kampung Cireungit, Garut, and the relationship between the delivery of the speech and the cultural values of the society.

Key Words: speech acts, syarah (explanation) of Al-Hikam, interpretation of the Koran, etnopragmatic, cultural values.
\end{abstract}




\section{PENDAHULUAN}

Bahasa adalah hasil budaya suatu masyarakat berupa sistem lambang bunyi ujaran yang kompleks dan aktif. Kompleks, karena ujaran tersebut mengandung pemikiran-pemikiran kolektif yang dimiliki oleh suatu masyarakat. Aktif, karena ujaran tersebut terus berubah sesuai dengan perkembangan masyarakat. Oleh karena sifatnya tersebut, bahasa adalah aspek penting dalam mempelajari suatu kehidupan dan kebudayaan masyarakat.

Wujud penggunaan bahasa ini biasa terealisasi lewat tindak tutur.Tindak tutur yang disampaikan kiai merupakan model komunikasi pertama yang terjadi dalam kehidupan masyarakat. Secara teoretis, tindak tutur telah menjadi ekspresi estetik masyarakat Indonesia. Sistem-sistem kepercayaan, nilai adat-istiadat, sikap, pandangan hidup, organisasi sosial, sejarah, dan kesenian disampaikan lewat tindak tutur. Secara praktis, tindak tutur banyak digunakan para pemuka adat atau tokoh masyarakat untuk mempertahankan kebudayaannya. Nilai-nilai perilaku budaya diwariskan melalui institusi sosial seperti agama dan pendidikan, yang merupakan pranata kebudayaan yang menjamin perilaku masyarakat. Jadi, bisa dikatakan bahwa pangkal akar budaya masyarakat berawal dari tindak tutur (Mahayana, 2012: 1)

Untuk menjamin perilaku masyarakatnya, kiai harus menguasai selukbeluk tindak tutur. Fungsi penggunaan bahasa memaksa kiai untuk menciptakan batasan, menyatukan para penuturnya (ibuibu di pengajian) sebagai anggota masyarakat tutur, dan mengesampingkan orang asing (outsiders) dari komunikasi intrakelompok (Syukur: 1992: 15). Fungsi penggunaan bahasa tersebut mewujud dalam suatu tindak tutur. Bagaimana penggunaan bahasanya dan kaitan antara penyampaian tuturan kiai dengan nilai-nilai budaya masyarakatnya sangat penting dikuasai oleh kiai. Sebagai pembelajar bahasa, kita dapat memetik pelajaran berharga dari fenomena tindak tutur kiai ini.

Penelitian tindak tutur sebelumnya telah dilakukan oleh Liana (2012) menghasilkan temuan bahwa tindak tutur dalam khotbah bahasa Batak Toba di Gereja HKBP Solo terdapat tujuh jenis tindak tutur, yaitu: fatis, performatif, komisif, ekspresif, verdiktif, asertif dan direktif. Dapat dikatakan, temuan Liana untuk menghasilkan teori bahwa kalimat-kalimat penanda untuk mengidentifikasi tindak tutur diistilahkan sebagai subtindak tutur. Kemudian penelitian yang relevan lainnya dilakukan Masfufah (2010) yang hanya menyoroti bentuk kesantunan tindak tutur direktif, prinsip kesantunan tindak tutur direktif, urutan kesantunan tindak tutur direktif siswa dan guru dalam persepsi siswa, dan faktor yang menentukan kesantunan dan ketidaksantunan bentuk tuturan direktif. Penelitian ini cukup menarik karena untuk melihat dampak dari tindak tutur yang dilakukan siswa dan guru, peneliti mengukurnya dengan persepsi siswa. Demikianlah, berbagai penelitian dikembangkan untuk sebuah temuan baru dalam ilmu bahasa pragmatik, khususnya tindak tutur.

\section{METODE}

Metode penelitian ini menggunakan metode kualitatif. Metode kualitatif menghasilkan data deskriptif berupa katakata tertulis atau lisan dari orang-orang atau perilaku yang dapat diamati (Bogdan\& Taylor dalam Moleong, 2003). Karakteristik dalam penelitian ini menggunakan metode deskriptif analitik etnopragmatik.

Teknik pengumpulan data dalam penelitian ini menggunakan teknik berupa instrumen: (1) observasi partisipan; (2) teknik simak-rekam-catat; (3) dan 
wawancara. Teknik (1) yaitu observasi partisipan adalah observasi yang melibatkan peneliti secara langsung dalam kegiatan pengamatan di lapangan. Teknik (2) simakrekam-catat adalah teknik yang dimulai dengan menyimak, kemudian merekam tuturan kiai mengenai syarah (penjelasan) kitab Al-Hikam dan tafsir Al-Qur'an. Hasil rekaman dicatat untuk kemudian dianalisis dan dideskripsikan.Teknik (3) wawancara adalah usaha memperoleh informasi dari narasumber. Narasumber dalam penelitian ini adalah Kiai Amin.

Korpus data diambil dari bulan Oktober 2012 hingga bulan April 2013. Data tindak tutur kiai yang akan diteliti yaitu data tanggal 29 Oktober 2012, yakni tindak tutur kiai mengenai syarah (penjelasan) kitab AlHikam No. 48 (Bahreisy, 1980: 46); data tanggal 3 April 2013, yakni tindak tutur kiai mengenai tafsir Al-Qur'an Surat Hud Ayat 54-58; dan data tanggal 5 April 2013, yakni tindak tutur kiai mengenai tafsir Al-Qur'an Surat Hud Ayat 58-60; dan data tanggal 16 April 2013, yakni tindak tutur kiai mengenai syarah (penjelasan) kitab Al-Hikam No.70 (Bahreisy, 1980: 64).

Dalam mengolah data peneliti menggunakan teori tindak tutur Leech (1983), teori implikatur Levinson (1982), dan teori etnopragmatik Goddard (2002).

\section{Tabel 1}

\section{Bentuk Analisis Jenis Tindak Tutur Kiai}

\begin{tabular}{|c|c|c|c|}
\hline No & Jenis Data & VerbaTuturan & Jenis Tuturan \\
\hline 1. & (KA-1/1) & $\begin{array}{l}\text { Jangan mengajukan permintaan } \\
\text { kepada Allah untuk dikeluarkan } \\
\text { dari salah satu keadaan untuk } \\
\text { dijadikan seperti seorang yang } \\
\text { beramal dalam keadaan yang } \\
\text { lainnya }\end{array}$ & Direktif \\
\hline 2. & $(\mathrm{TA}-1 / 1)$ & $\begin{array}{l}\text { Innaquulu tiada lain yang } \\
\text { diceritakan oleh kami illaa taroka } \\
\text { kecuali sudah menimpakan } \\
\text { kepadamu ba'du aalihatina dari } \\
\text { sebagian sesembahan kami bisuu } \\
\text { in dengan kejelekan. Yang } \\
\text { dimaksud dengankejelekan } \\
\text { disini sebagaimana biasa dalam } \\
\text { bahasa dikalangan mereka } \\
\text { sama dengan perkataan yang } \\
\text { berlaku di kita istilahnya } \\
\text { penyakit atau kewalat }\end{array}$ & Asertif \\
\hline$\ldots$ & $\ldots$ & $\ldots$ & $\ldots$ \\
\hline$\ldots$ & $\ldots$ & $\ldots$ & $\ldots$ \\
\hline$\ldots$ & $\ldots$ & $\ldots$ & $\ldots$ \\
\hline
\end{tabular}

Keterangan:

Kode (KA-1/1) :Jenis data tuturan syarah (penjelasan) kitab Al-Hikam data pertama kalimat pertama. Data (KA-1/1) dianalisis sebagai jenis tuturan direktif karena ditandai dengan tindakan 'memberi nasehat' seperti yang ditunjukkan verba "jangan mengajukan".

Kode (TA-1/1): Jenis data tuturan tafsir AlQur' an data pertama kalimat pertama. Data (TA1/1) dianalisis sebagai jenis tuturan asertif 
karena ditandai dengan tindakan 'mengemukakan pendapat' seperti yang ditunjukkan verba "yang dimaksud dengan kejelekan di sini sebagaimana biasa dalam bahasa di kalangan mereka sama dengan perkataan yang berlaku di kita istilahnya penyakit atau kewalat".

\section{Tabel 2}

Bentuk Analisis Tipe Tindak Tutur Kiai

TipeTindakTutur: Langsung Literal

\begin{tabular}{|c|c|c|c|c|}
\hline No & Jenis Data & Pelibat & Verba Tuturan & Makna Tuturan \\
\hline 1. & $(\mathrm{KA}-1 / 1)$ & $\begin{array}{ll}\text { Kiai, } & \text { Ibu- } \\
\text { ibu, } & \text { dan } \\
\text { Allah } & \\
\text { SWT } & \end{array}$ & $\begin{array}{l}\text { Jangan mengajukan } \\
\text { permintaan kepada } \\
\text { Allah untuk dikeluarkan } \\
\text { dari salah satu keadaan } \\
\text { untuk dijadikan seperti } \\
\text { seorang yang beramal } \\
\text { dalam keadaan yang } \\
\text { lainnya }\end{array}$ & $\begin{array}{lr}\text { Dilarang mengajukan } \\
\text { permintaan kepada } \\
\text { Allah di luar yang } \\
\text { dikehendaki-Nya }\end{array}$ \\
\hline 2. & $(\mathrm{TA}-1 / 1)$ & $\begin{array}{ll}\text { Kiai, } & \text { Ibu- } \\
\text { ibu, } & \text { dan } \\
\text { Allah } & \\
\text { SWT } & \end{array}$ & 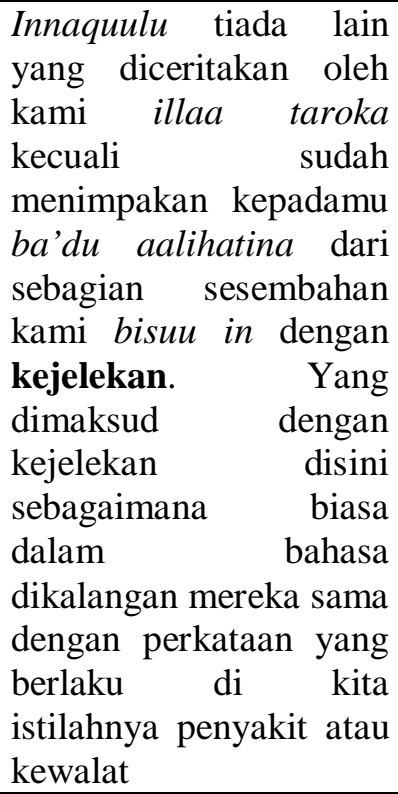 & $\begin{array}{l}\text { Maksud dari kejelekan } \\
\text { menurut kaum kafir } \\
\text { yaitu penyakit atau } \\
\text { kewalat. }\end{array}$ \\
\hline$\ldots$ & $\ldots$ & $\ldots$ & $\ldots$ & $\ldots$ \\
\hline$\ldots$ & $\ldots$ & $\ldots$ & $\ldots$ & $\ldots$ \\
\hline$\ldots$ & $\ldots$ & $\ldots$ & $\ldots$ & \\
\hline
\end{tabular}

Dikatakan tipe tindak tutur langsung literal karena memiliki modus dan makna semantis leksikon yang sama antara apa yang dituturkan kiai dengan apa yang ditangkap oleh ibu-ibu. Verba "Jangan mengajukan permintaan kepada Allah untuk dikeluarkan dari salah satu keadaan untuk dijadikan seperti seorang yang beramal dalam keadaan yang lainnya" pada kalimat tuturan mengenai syarah (penjelasan) kitab AlHikam data pertama kalimat pertama memiliki modus yang sama dengan makna yakni "Dilarang mengajukan permintaan kepada Allah di luar yang dikehendakiNya". 
Kemudian, verba tuturan mengenai tafsir Al-Qur'an data pertama kalimat pertama yaitu "Innaquulu tiada lain yang diceritakan oleh kami illaa taroka kecuali sudah menimpakan kepadamu $b a^{\prime} d u$ aalihatina dari sebagian sesembahan kami bisuu in dengan kejelekan. Yang dimaksud dengan kejelekan disini sebagaimana biasa dalam bahasa dikalangan mereka sama dengan perkataan yang berlaku di kita istilahnya penyakit atau kewalat" memiliki modus yang sama yaitu "Maksud dari kejelekan menurut kaum kafir yaitu penyakit atau

kewalat".

\section{Tabel 3}

Tipe Tindak Tutur: Langsung Tidak Literal

\begin{tabular}{|l|l|l|l|l|}
\hline No & Jenis Data & \multicolumn{1}{|c|}{ Pelibat } & \multicolumn{1}{|c|}{ Verba Tuturan } & \multicolumn{1}{c|}{ Makna Tuturan } \\
\hline 1. & $($ KA-1/3) & $\begin{array}{l}\text { Kiai, Ibu- } \\
\text { ibu, dan, } \\
\text { Allah } \\
\text { SWT }\end{array}$ & $\begin{array}{l}\text { Tuhan jika saya } \\
\text { sembuh, sepertinya } \\
\text { saya bisa berangkat ke } \\
\text { pengajian ke sana ke } \\
\text { mari dan melakukan } \\
\text { amal ini dan itu }\end{array}$ & $\begin{array}{l}\text { Baru 'sepertinya', } \\
\text { bagaimana bila ia } \\
\text { sembuh dan tetap tidak } \\
\text { beribadah? }\end{array}$ \\
\hline 2. & $($ TA-1/2) & $\begin{array}{l}\text { Kiai, Ibu- } \\
\text { ibu, dan } \\
\text { Allah } \\
\text { SWT }\end{array}$ & $\begin{array}{l}\text { Jadi yang diceritakan } \\
\text { oleh Kami tiada bukan } \\
\text { bahwa sebagian } \\
\text { sesembahan kami telah } \\
\text { menimpakan penyakit } \\
\text { kepada kalian. }\end{array}$ & $\begin{array}{l}\text { Perkataan Kaum 'Ad di } \\
\text { kaman Nabi Hud } \\
\text { mengajak untuk } \\
\text { menyembah Allah } \\
\text { SWT. }\end{array}$ \\
\hline$\ldots$ & $\ldots$ & $\ldots$ & $\ldots$ & $\ldots$ \\
\hline$\ldots$ & $\ldots$ & $\ldots$ & $\ldots$ & $\ldots$ \\
\hline
\end{tabular}

Dikatakan tipe tindak tutur langsung tidak literal karena meskipun modus tuturannya sama, akan tetapi makna tuturan yang dimaksud kiai bukan seperti itu. Misalnya verba tuturan mengenai syarah (penjelasan) kitab Al-Hikam pertama kalimat ketiga, "Tuhan jika saya sembuh, sepertinya saya bisa berangkat ke pengajian ke sana ke mari dan melakukan amal ini dan itu" memiliki makna bahwa "Baru 'sepertinya', bagaimana bila ia sembuh dan tetap tidak beribadah?". Kiai mengatakan ini mempunyai modus untuk mengingatkan apakah kita suka bersikap demikian, untuk beribadah saja harus mengajukan syarat.

Kemudian, verba tuturan mengenai tafsir Al-Qur'an pertama kalimat kedua yaitu "Jadi yang diceritakan oleh Kami tiada bukan bahwa sebagian sesembahan kami telah menimpakan penyakit kepada kalian" bukanlah perintah untuk menyembah sesembahan supaya tidak ditimpa penyakit sebagaimana makna harfiahnya melainkan merupakan "Perkataan Kaum 'Ad di zaman Nabi Hud karena nabi Hud mengajak untuk menyembah Allah SWT". 
Tabel 4

Tipe Tindak Tutur: Tidak Langsung Literal

\begin{tabular}{|c|c|c|c|c|}
\hline No & Jenis Data & Pelibat & Verba Tuturan & Makna Tuturan \\
\hline 1. & $(\mathrm{KA}-1 / 5)$ & $\begin{array}{lr}\text { Kiai, } & \text { Ibu- } \\
\text { ibu, } & \text { dan } \\
\text { Allah } & \\
\text { SWT } & \end{array}$ & \begin{tabular}{l}
\multicolumn{2}{l}{ Ketidakadaan amalnya } \\
karena dia sakit dan \\
ketika dia diberi sakit \\
bukannya tidak mau \\
beramal. Tidak kuat \\
ketika \\
menakdirkan sakit dan \\
tidak ada perubahan. \\
\end{tabular} & $\begin{array}{l}\text { Ia tetap tidak beramal } \\
\text { saat sehat }\end{array}$ \\
\hline 2. & (TA-1/3) & $\begin{array}{ll}\text { Kiai, } & \text { Ibu- } \\
\text { ibu, } & \text { dan } \\
\text { Allah } & \\
\text { SWT } & \end{array}$ & $\begin{array}{l}\text { Hal ini bukan hanya } \\
\text { terjadi pada Nabi Hud } \\
\text { termasuk kepada Nabi } \\
\text { Muhammad juga } \\
\text { banyak yang berbicara } \\
\text { seperti itu sehingga } \\
\text { Alloh membuat tenang } \\
\text { Nabi Muhammad pada } \\
\text { surat Al-Qolam maa } \\
\text { anta bini'mati robbika } \\
\text { bimajnuun tidak jika } \\
\text { kamu itu oleh nikmat } \\
\text { dari Tuhan kamu, nah } \\
\text { ni'mati robbika disini } \\
\text { artinya agama islam } \\
\text { bimajnuunin yaitu gila }\end{array}$ & $\begin{array}{l}\text { Semua nabi didustakan } \\
\text { kaumnya, termasuk } \\
\text { Nabi Hud \& Nabi } \\
\text { Muhammad SAW. }\end{array}$ \\
\hline$\ldots$ & $\ldots$ & $\ldots$ & $\ldots$ & $\ldots$ \\
\hline$\ldots$ & $\ldots$ & $\ldots$ & $\ldots$ & $\ldots$ \\
\hline$\ldots$ & $\ldots$ & $\ldots$ & & $\ldots$ \\
\hline
\end{tabular}

Dikatakan tipe tindak tutur tidak langsung literal karena tidak sesuai dengan maksud meskipun makna leksikonnya sama. Misalnya verba tuturan mengenai syarah (penjelasan) kitab Al-Hikam pertama kalimat kelima yaitu "Ketidakadaan amalnya karena dia sakit dan ketika dia diberi sakit bukannya tidak mau beramal. Tidak kuat ketika Allah menakdirkan sakit dan tidak ada perubahan" memiliki makna "Ia tetap tidak beramal saat sehat" bermodus bahwa manusia suka membuat alasan. Kemudian verba tuturan mengenai tafsir AlQur'an pertama kalimat ketiga, "Hal ini bukan hanya terjadi pada Nabi Hud termasuk kepada Nabi Muhammad juga banyak yang berbicara seperti itu sehingga Alloh membuat tenang Nabi Muhammad pada surat Al-Qolam maa anta bini'mati robbika bimajnuun tidak jika kamu itu oleh nikmat dari Tuhan kamu, nah ni'mati robbika disini artinya agama islam bimajnuunin yaitu gila" memiliki makna, "Semua nabi didustakan kaumnya, termasuk Nabi Hud \& Nabi Muhammad SAW". Tuturan ini bermodus bahwa orang gila tidak akan merasakan nikmatnya beragama Islam". 
Tabel 5

Tipe Tindak Tutur: Tidak Langsung Tidak Literal

\begin{tabular}{|c|c|c|c|c|}
\hline No & Jenis Data & Pelibat & Verba Tuturan & Makna Tuturan \\
\hline 1. & $\begin{array}{l}\text { (KA- } \\
1 / 2)\end{array}$ & $\begin{array}{lr}\text { Kiai, } & \text { Ibu- } \\
\text { ibu, } & \text { dan } \\
\text { Allah } & \\
\text { SWT } & \end{array}$ & $\begin{array}{l}\text { Tuhan jika saya } \\
\text { sembuh, sepertinya } \\
\text { saya bisa berangkat ke } \\
\text { pengajian ke sana ke } \\
\text { mari dan melakukan } \\
\text { amal ini dan itu }\end{array}$ & Mengeluh \\
\hline 2. & (TA-1/4) & $\begin{array}{ll}\text { Kiai, } & \text { Ibu- } \\
\text { ibu, } & \text { dan } \\
\text { Allah } & \\
\text { SWT } & \end{array}$ & $\begin{array}{l}\text { Sebab banyak yang } \\
\text { memaknai bahwa } \\
\text { manusia yang mengajak } \\
\text { menurutkan wahyu itu } \\
\text { dipandangnya manusia } \\
\text { sesat. }\end{array}$ & $\begin{array}{l}\text { Bila mengikuti ajakan } \\
\text { nabi Hud a.s berarti } \\
\text { sesat, padahal } \\
\text { ajakannya itu benar. }\end{array}$ \\
\hline$\ldots$ & $\ldots$ & $\ldots$ & $\ldots$ & $\ldots$ \\
\hline$\ldots$ & $\ldots$ & $\ldots$ & $\ldots$ & $\ldots$ \\
\hline$\ldots$ & $\ldots$ & $\ldots$ & $\ldots$ & $\ldots$ \\
\hline
\end{tabular}

Dikatakan tipe tindak tutur tidak langsung tidak literal karena modus tuturan dan makna leksikonnya tidak sama. Verba tuturan mengenai syarah (penjelasan) kitab Al-Hikam pertama ayat kedua, "Tuhan jika saya sembuh, sepertinya saya bisa berangkat ke pengajian ke sana ke mari dan melakukan amal ini dan itu." Memiliki makna mengeluh. Modusnya untuk memperlihatkan bahwa manusia memang suka berkeluh kesah dan mencari-cari alasan/ berangan- angan. Ini ditandai dengan kata 'jika'. Kemudian, verba tuturan mengenai tafsir AlQur'an pertama ayat keempat, "Sebab banyak yang memaknai bahwa manusia yang mengajak menurutkan wahyu itu dipandangnya manusia sesat" memiliki makna "Bila mengikuti ajakan nabi Hud a.s berarti sesat, padahal ajakannya itu benar". Modusnya untuk memperlihatkan bahwa kaum 'Ad sebagaimana kaum yang lain adalah kaum yang bodoh lagi keras kepala.

Tabel 6

Bentuk Analisis Kaitan antara Penyampaian Tuturan Kiai dengan Nilai-nilai Budaya Masyarakatnya

\begin{tabular}{|l|l|l|l|}
\hline No & Jenis Data & \multicolumn{1}{|c|}{ Kalimat Tuturan } & Nilai Budaya \\
\hline 1. & $($ KA-1/1) & $\begin{array}{l}\text { Jangan mengajukan permintaan kepada } \\
\text { Allah untuk dikeluarkan dari salah satu } \\
\text { keadaan untuk dijadikan seperti seorang } \\
\text { yang beramal dalam keadaan yang lainnya }\end{array}$ & Keikhlasan \\
\hline 2. & $($ TA-1/1) & $\begin{array}{l}\text { Innaquulu tiada lain yang diceritakan oleh } \\
\text { kami illaa taroka kecuali sudah } \\
\text { menimpakan kepadamu ba'du aalihatina }\end{array}$ & Religius \\
\hline
\end{tabular}




\begin{tabular}{|c|c|l|l|}
\hline & & $\begin{array}{l}\text { dari sebagian sesembahan kami bisuu in } \\
\text { dengan kejelekan. Yang dimaksud } \\
\text { dengan kejelekan disini sebagaimana } \\
\text { biasa dalam bahasa dikalangan mereka } \\
\text { sama dengan perkataan yang berlaku di } \\
\text { kita istilahnya penyakit atau kewalat }\end{array}$ & \\
\hline$\ldots$ & $\ldots$ & $\ldots$ & $\ldots$ \\
\hline$\ldots$ & $\ldots$ & $\ldots$ & $\ldots$ \\
\hline$\ldots$ & $\ldots$ & $\ldots$ & \\
\hline
\end{tabular}

Kalimat tuturan mengenai syarah (penjelasan) kitab Al-Hikam data pertama ayat pertama yaitu "Jangan mengajukan permintaan kepada Allah untuk dikeluarkan dari salah satu keadaan untuk dijadikan seperti seorang yang beramal dalam keadaan yang lainnya" memiliki nilai keikhlasan. Hal ini dikarenakan kita dituntut ikhlas beribadah pada Allah SWT apapun kondisinya.Kemudian,kalimat tuturan mengenai tafsir Al-Qur'an data pertama ayat pertama yaitu "Innaquulu tiada lain yang diceritakan oleh kami illaa taroka kecuali sudah menimpakan kepadamu $b a$ 'du aalihatina dari sebagian sesembahan kami bisuu in dengan kejelekan. Yang dimaksud dengan kejelekan disini sebagaimana biasa dalam bahasa dikalangan mereka sama dengan perkataan yang berlaku di kita istilahnya penyakit atau kewalat." bermakna religius karena dituntut untuk memiliki rasa keimanan yang tinggi ketika ada fitnah/ ancaman datang.

\section{HASIL DAN PEMBAHASAN}

Kajian tindak tutur pertama kali diperkenalkan oleh Austin (1962) dan Searle $(1969,1975,1983)$, yang memandang bahwa bahasa digunakan untuk melakukan tindakan. Teori tindak tutur telah mengarah pada bagaimana sebuah pengucapan dapat dilakukan lebih dari satu tindak tutur pada saat yang bersamaan, dan hubungan antara konteks dan tindakan (Schiffrin, 1994:50).

Senada dengan Sciffrin, Searle (1969) dan Edmondson (1981) mengatakan tindak tutur adalah sesuatu yang secara nyata dilakukan ketika seseorang berbicara atau unit minimal yang dapat dikemukakan untuk mengusung fungsi tertentu.Tindak tutur dihasilkan ketika pembicara/ penulis membuat tuturan kepada pendengar/ pembaca dalam konteks tertentu (Allan, 1998).

Kridalaksana (2000: 171) mendefinisikan tindak tutur sebagai bentuk perbuatan berbahasa yang diwujudkan sesuai kaidah pemakaian unsur-unsur bahasa.Tindak tutur juga melibatkan partisipan, bentuk penyampaian tuturan, topik, dan konteks dari tuturan tersebut. Namun, terkadang, tindak tutur digunakan untuk menyatakan suatu maksud tertentu dari penutur. Jadi, fungsi kalimat di sini tidak hanya menggambarkan suatu keadaan atau untuk menyatakan suatu fakta, tetapi dapat pula diujarkan untuk menyatakan atau melaporkan suatu tindakan (Austin, 1962: 5).

Penafsiran tindak tutur jauh lebih banyak ditemukan dibandingkan makna yang terdapat dalam tuturan itu sendiri. Hal ini dikarenakan tindak tutur sangat tergantung dengan konteks ketika penutur bertutur.Tuturan-tuturan baru dapat dimengerti hanya dalam kaitannya dengan kegiatan yang menjadi konteks dan tempat tuturan itu terjadi. Sesuai dengan pendapat Alwasilah (1993:20), bahwa ujaran bersifat tergantung konteks (context dependent).

Ada tiga kategori tindak tutur berdasarkan sifat antara hubungan penutur 
dengan lawan tutur yakni: tindak lokusi (locutionary acts), tindak ilokusi (illocutionary acts), dan tindak perlokusi (perlocutionary acts) (Austin dalam Searle, 1975: 23-24; Levinson, 1982: 236). Implikatur konvensional digunakan untuk melihat makna ilokusional berdasarkan tuturan langsung dan literal sedangkan implikatur konversasional digunakan untuk melihat segi makna berdasarkan tuturan tidak langsung dan tidak literal. Makna ilokusional sebuah tuturan adalah sumber utama makna lokusional dan perlokusional. Untuk dapat melihat makna ilokusional dalam tindak tutur kiai mengenai syarah (penjelasan) kitab Al-Hikam dan tafsir AlQur'an pada ibu-ibu pengajian di masjid Nurul Huda Kampung Cireungit Garut, diperlukan hasil interpretasi hubungan dan konteks penggunaannya dengan memperhatikan pemahaman proses komunikasi, tindak komunikasi, pilihan makna dan konteks, pragmatik, dan situasi kontekstual.

Etnopragmatik merupakan gabungan ilmu etnografi dan pragmatik. Etnografi merupakan ilmu yang menyoroti tentang etnik atau kelompok masyarakat atau komunitas tertentu. Pragmatik adalah ilmu linguistik yang memfokuskan kajian pada makna bahasa dalam penggunaannya yang terikat konteks dan situasi. Jadi, etnopragmatik adalah membicarakan kaitan antara penyampaian tuturan kiai dengan nilai-nilai budaya masyarakat (Fauziah, 2003).

Etnopragmatik ini digunakan untuk memahami makna ilokusional berdasarkan budaya masyarakat sehingga tindak tutur kiai mengenai syarah (penjelasan) kitab AlHikam dan Tafsir Al-Qur'an pada ibu-ibu pengajian di masjid Nurul Huda Kampung Cireungit Garut dalam hal nilai-nilai kearifan lokal, kepercayaan, perilaku, kategori sosial, emosi, dan lainnya dapat dipahami (Goddard, 2002). Karena, suatu tindak tutur dari sudut pandang budaya internal memiliki banyak penafsiran.Pada pihak tertentu, ciri-ciri sosial komunikasi dapat dilihat sebagai suatu rangkaian hubungan dan memiliki peranan dalam taraf sosial hirarki yang jelas. Namun di pihak lain, ciri-ciri itu membentuk suatu konsepsi tertib sosial. Artinya, dari segi budaya ciriciri itu dapat ditafsirkan dan dijelaskan menurut aturan norma.

Kajian etnopragmatik ialah tindakan pertuturan, seperti yang dikonsepsikan dalam teori tindakan pertuturan Austin (1962). Kajian tindak tutur menjadi objek penelitian etnopragmatik karena dapat memperlihatkan kaitan antara penyampaian tuturan kiai dengan nilai-nilai budaya yang terdapat dalam masyarakat tersebut.

Jenis tuturan yang terdapat dalam tindak tutur kiai mengenai syarah (penjelasan) kitab Al-Hikam dan Tafsir AlQur'an pada ibu-ibu pengajian di masjid Nurul Huda Kampung Cireungit Garut dapat dijelaskan sebagai berikut:

Berdasarkan teori tindak tutur Leech (1983), data (KA-1/1) dianalisis sebagai jenis tuturan direktif karena ditandai dengan tindakan 'memberi nasehat' seperti yang ditunjukkan verba "jangan mengajukan". Data (KA-1/2) dianalisis sebagai jenis tuturan direktif karena ditandai dengan tindakan ' memberi nasehat' seperti yang ditunjukkan verba "menghendaki amal, niscaya Allah menghendaki amal tersebut kepadamu". Data (KA-1/3) dianalisis sebagai jenis tuturan komisif karena ditandai dengan tindakan 'menawarkan' seperti yang ditunjukkan verba "Tuhan, jika saya sembuh, sepertinya saya bisa berangkat ke pengajian ke sana ke mari dan melakukan amal ini dan itu".

Tindak tutur asertif adalah tindak tutur yang paling dominan yang tersebar dalam tindak tutur kiai mengenai syarah (penjelasan) kitab Al-Hikam dan Tafsir Al- 
Qur'an pada ibu-ibu pengajian di masjid Nurul Huda Kampung Cireungit Garut. Hal ini dikarenakan penutur atau Kiai banyak menggunakan proposisi menyatakan, mengusulkan, membuat, mengeluh, mengemukakan pendapat, dan melaporkan. Meskipun demikian, seperti halnya agama pada umumnya, tindak tutur direktif dan deklaratif pun hampir dominan dalam wacana tutur. Karena memang, fungsi agama yang mengikat para penganutnya.

Dikatakan tipe tindak tutur langsung literal karena memiliki modus dan makna semantik leksikon yang sama antara apa yang dituturkan kiai dengan apa yang ditangkap oleh ibu-ibu (Levinson, 1982). Verba "Jangan mengajukan permintaan kepada Allah untuk dikeluarkan dari salah satu keadaan untuk dijadikan seperti seorang yang beramal dalam keadaan yang lainnya" pada kalimat tuturan mengenai syarah (penjelasan) kitab Al-Hikam data pertama kalimat pertama memiliki modus yang sama dengan makna yakni "Dilarang mengajukan permintaan kepada Allah di luar yang dikehendaki-Nya".

Verba "Jika Allah menghendaki amal tersebut kepadamu niscaya Allah menghendaki amal tersebut kepadamu" pada kalimat tuturan mengenai syarah (penjelasan) kitab Al-Hikam data pertama kalimat kedua memiliki modus yang sama dengan makna yakni "Allah menghendaki amal dari hamba-Nya". Verba "Keluhan tersebutlah yang tidak boleh karena itu hanyalah fatamorgana jika manusia tersebut ditakdirkan sehat" pada kalimat tuturan mengenai syarah (penjelasan) kitab $A l$ Hikam data pertama kalimat keempat memiliki modus yang sama dengan makna yakni "tidak boleh berandai-andai". Verba "itulah yang dimaksud bahwa anda jangan sekuatnya meminta keluar dari keadaan anda apa adanya" pada kalimat tuturan mengenai syarah (penjelasan) kitab Al-Hikam data pertama kalimat keenam memiliki modus yang sama dengan makna yakni "dilarang meminta keluar dari keadaan dengan apa adanya". Verba "karena itulah manusia seolah-olah ingin keluar dari segala keadaannya yang tidak diharapkan" pada kalimat tuturan mengenai syarah (penjelasan) kitab Al-Hikam data pertama kalimat kedelapan memiliki modus yang sama dengan makna yakni "manusia ingin keluar dari keadaan yang tak diharapkan”.

Dikatakan tipe tindak tutur langsung tidak literal karena modus tuturnya sama akan tetapi makna tuturan yang dimaksud kiai bukan seperti itu. Misalnya verba tuturan mengenai syarah (penjelasan) kitab Al-Hikam pertama kalimat ketiga, "Tuhan jika saya sembuh, sepertinya saya bisa berangkat ke pengajian ke sana ke mari dan melakukan amal ini dan itu" memiliki makna bahwa "Baru sepertinya, bagaimana bila ia sembuh dan tetap tidak beribadah?" Kiai mengatakan ini mempunyai modus untuk mengingatkan apakah kita suka bersikap demikian, untuk beribadah saja harus mengajukan syarat.

Kemudian verba tuturan mengenai syarah (penjelasan) kitab Al-Hikam pertama kalimat ketujuh, "Tuhan, iri rasanya pada orang-orang yang kaya tetapi saya miskin" memiliki makna "memohon kaya". Kiai mengatakan ini mempunyai modus untuk mengingatkan apakah kita suka bersikap demikian, selalu iri dengan rezeki orang lain. Verba tuturan mengenai syarah (penjelasan) kitab Al-Hikam pertama kalimat kesembilan, "Padahal dari keadaan itulah banyak sisi positif yang bisa dijadikan sebagai ladang ibadah" memiliki makna "Jadikan segala sesuatunya bernilai ibadah". Kiai mengatakan ini mempunyai modus untuk selalu beribadah baik dalam keadaan sehat maupun sakit, lapang maupun sempit.

Dikatakan tipe tindak tutur tidak langsung tidak literal karena modus tuturan dan makna leksikonnya tidak sama. Verba tuturan mengenai syarah (penjelasan) kitab 
Al-Hikam pertama kalimat kelima, "Ketidakadaan amalnya karena dia sakit dan ketika dia diberi sakit bukannya tidak mau beramal. Tidak kuat ketika Allah menakdirkan sakit dan tidak ada perubahan" memiliki makna "Ia tetap tidak beramal saat sehat". Kiai mengatakan ini mempunyai modus kita bisa beramal dengan berbagai kondisi.

Tipe tindak tutur yang paling dominan adalah tindak tutur langsung literal. Tindak tutur kiai mengenai syarah (penjelasan) kitab Al-Hikam dan Tafsir AlQur'an pada ibu-ibu pengajian di masjid Nurul Huda Kampung Cireungit Garut banyak menggunakan tipe tindak tutur langsung literal yang mempunyai arti tuturan yang bermodus sama, yang diutarakan dengan kata-kata yang memiliki makna semantis leksikon yang sama dalam membangun tuturan tersebut (Levinson, 1983). Hal ini sangat penting dalam memberikan informasi komunikasi yang sifatnya mengikat dan mempunyai pengaruh kuat.Tindak tutur langsung menunjukkan fungsinya dalam keadaan tindakan langsung dan literal, penuturan sesuai dengan kenyataan.

Contoh tuturan (KA-1/1), "Jangan mengajukan permintaan kepada Allah untuk dikeluarkan dari salah satu keadaan untuk dijadikan seperti seorang yang beramal dalam keadaan yang lainnya" yang mengandung nilai keikhlasan. Tuturan (KA1/2), “ ..jika Allah menghendaki amal tersebut kepadamu niscaya Allah menghendaki amal tersebut kepadamu" mengandung nilai kesabaran. Tuturan (KA1/3), "Tuhan jika saya sembuh, sepertinya saya bisa berangkat ke pengajian ke sana ke mari dan melakukan amal ini dan itu" mengandung nilai keta'atan. Tuturan (KA1/8), "Karena itulah manusia seolah-olah ingin keluar dari segala keadaannya yang tak diharapkan." mengandung nilai kemanusiaan. Tuturan (KA-1/9), "Padahal dari keadaan itulah banyak sisi positif yang bisa dijadikan sebagai ladang ibadah." mengandung nilai kearifan. Tuturan (TA1/30), "Jadi, kalau kalian menghindar, maka tidak akan merugikan saya, kata Nabi Hud, karena yang akan rugi itu adalah kalian sendiri. Jadi bukan untuk keuntungan Nabi Hud." mengandung nilai keharmonisan. Tuturan (TA-1/31), "Itulah yang disebut dengan ketulusan dalam perjalanan agama, tidak pernah melihat kepada keuntungan pribadinya akan tetapi dilakukan sematamata untuk membangun keuntungan semua manusia, terlebih lagi orang yang paling dekat, yang disayangi." mengandung nilai solidaritas.

\section{SIMPULAN DAN SARAN}

Berdasarkan hasil penelitian yang telah dilaksanakan sejak bulan Oktober 2012 hingga bulan April 2013, maka diperoleh simpulan sebagai berikut: (a) jenis tindak tutur kiai banyak menggunakan jenis tindak tutur ilokusi asertif daripada direktif karena pada dasarnya masyarakat pemeluk agama lebih suka diajak daripada diperintah; (b) tipe tindak tutur yang paling banyak adalah tipe tindak tutur langsung literal. Tipe tindak tutur langsung literal sangat penting peranannya dalam pemberian informasi komunikasi yang sifatnya mengikat dan mempunyai pengaruh kuat. Kitab Al-Hikam banyak mengandung pemikiran, pendapat para ahli sufi untuk hamba yang ingin lebih mendekatkan diri pada Allah SWT. Di dalamnya terkandung tasawuf yang memiliki banyak pernyataan untuk direnungkan, DAN; (c) kaitan antara penyampaian tuturan kiai di masjid Nurul Huda Kampung Cireungit Garut dengan nilai-nilai budaya dengan pendekatan etnopragmatik, banyak terkandung nilai kesabaran, nilai kesederhanaan, nilai religius, nilai kemanusiaan, nilai kearifan, 
nilai keadilan, nilai solidaritas, nilai keta'atan, nilai keharmonisan, dan nilai keikhlasan. Etnopragmatik ini digunakan untuk memahami makna ilokusional berdasarkan budaya masyarakat sehingga tindak tutur kiai mengenai syarah (penjelasan) kitab Al-Hikam dan tafsir AlQur'an pada ibu-ibu pengajian di masjid Nurul Huda Kampung Cireungit Garut dapat dipahami. Berdasarkan hasil penelitian, peneliti menyarankan agar: (1) mahasiswa mampu menggali lagi kearifan lokal yang ada untuk wawasan keilmuan linguistik, khususnya etnopragmatik, dan ; (b) para pengajar menjadikan karya ilmiah sebagai referensi penelitian dan kajian pengembangan keilmuan linguistik, khususnya kajian tindak tutur dan etnopragmatik;

\section{UCAPAN TERIMA KASIH}

Terima kasih atas bimbingan Prof. Dr. Hj. Yoce Aliah Darma, M.Pd dan Dr. Dadang Anshori, M.Si selama peneliti menulis tesis ini. Kepada Dr. Sumiyadi, M.Hum selaku Ketua Jurusan Magister Pendidikan Bahasa Indonesia, yang telah menyemangati peneliti untuk terus menyelesaikan penelitian kualitatif ini. Tak lupa kepada Prof. Dr. Ahmad Slamet, M.A., M.Sc dan Prof. Dr. Syihabuddin atas perbaikan-perbaikan saat pengujian sidang. Pak Khaeruddin Kurniawan yang telah memberi masukan pada peneliti untuk mengambil judul penelitian ini. Kemudian, untuk Kiai Amin Kurnia, S.H.I dan ibu-ibu pengajian di Kampung Cireungit.

\section{PUSTAKA RUJUKAN}

Allan, K. 1998. The Meaning of Culture, Moving the Postmodern Critique
Forward. America: Praeger Publisher.

Alwasilah, A.C. 1993. "Bahasa Politik dan Politik Bahasa". Kompas (1 Oktober 1993)

Austin, J.L. 1962. Sense and Sensibilia. Oxford: Clarendon Press.

Bahreisy, Salim.1980. Terjemah Al-Hikam, Pendekatan Abdi pada Khaliqnya. Surabaya: Balai Buku.

Edmondson, W.1981. Spoken Discourse. England: Longman.

Fauziah.2003. Tesis untuk Suatu Etnopragmatik. [online]. Tersedia: repository.usu.ac.id/bitstream/.../1/ar ab-fauziah3.pdf [13 Mei 2013]

Goddard, C. 2002. "Directive Speech Acts in Malay. Ethnopragmatics

Persperctive in Special Issue on Intercultural Communication". Edited by Christine Beal 2003

Kridalaksana, H. 2000. Kamus Linguistik. Gramedia: Jakarta.

Liana. 2012. Tindak Tutur dalam Khotbah Bahasa Batak Toba di Gereja HKBP Solo Surakarta. Tesis Magister pada Prodi Linguistik Universitas Negeri Surakarta: tidak diterbitkan.

Leech, G.N. 1983. Principles of Pragmatics. England: Longman.

Levinson, S. 1982. Pragmatics. Cambridge: Cambridge University Press

Mahayana, M.S. 2012. Pucuk Gunung Es: Kelisanan dan Keberaksaraan dalam Kebudayaan Melayu-Indonesia dalam Resensi Kepustakaan Populer Gramedia dan Majalah Sastra Horison [online], Tersedia: http://www.gramedia.com/resensi/de tail/116/Pucuk+Gunung+Es\%3A+Ke lisanan+dan+Keberaksaraan+dalam+ Kebudayaan+Melayu-Indonesia.html [19 Februari 2013]

Masfufah.2010. Kesantunan Bentuk Tuturan Direktif di Lingkungan SMA Negeri 1 Surakarta. Tesis Magister pada Program Studi Magister Pendidikan 
bahasa Indonesia Universitas Negeri Surakarta: tidak diterbitkan.

Moleong, Lexy J. 2003. Meodologi Penelitian Kualitatif. Bandung: PT.Rosdakarya

Syukur, I. A. 1992. Panduan Penelitian Etnografi Komunikasi. Surabaya: Usaha Nasional.

Schiffrin, D. 1994. Approaches to Discourse. Cambridge: Cambridge University Press.
Searle, J. R. 1969. Speech Acts: An Essay Cambridge: Cambridge University Press.

Searle, John R. 1983. "Chomsky's revolution in linguistics". In Noam Chomsky: Critical essays.

Searle, J.1975. "Indirect Speech Acts". In: Cole and Morgan (eds.), Syntax and Semantics.Vol. 3. New York: Academic Press. 